\title{
Use of Plackett-Burman design for rapid screening of nitrogen and carbon sources for the production of lipase in solid state fermentation by Yarrowia lipolytica from mustard oil cake (Brassica napus)
}

\author{
Sarat Babu Imandi ${ }^{1,2}$, Sita Kumari Karanam ${ }^{3}$, Hanumantha Rao Garapati ${ }^{2,4}$ \\ ${ }^{1}$ Department of Biotechnology, GITAM Institute of Technology, GITAM University, Gandhinagar, \\ Visakhapatnam, AP, India. \\ ${ }^{2}$ Center for Biotechnology, Department of Chemical Engineering, Andhra University, Visakhapatnam, \\ AP, India. \\ ${ }^{3}$ M.R.College of Pharmacy, Phool Baugh, Vizianagaram, AP, India. \\ ${ }^{4}$ Department of Chemical Engg. \& Biotechnology, Anil Neerukonda Institute of Technology and \\ Sciences, Sangivalasa, Visakhapatnam, AP, India.
}

Submitted: August 11, 2010; Approved: November 13, 2012.

\begin{abstract}
Mustard oil cake (Brassica napus), the residue obtained after extraction of mustard oil from mustard oil seeds, was investigated for the production of lipase under solid state fermentation (SSF) using the marine yeast Yarrowia lipolytica NCIM 3589. Process parameters such as incubation time, biomass concentration, initial moisture content, carbon source concentration and nitrogen source concentration of the medium were optimized. Screening of ten nitrogen and five carbon sources has been accomplished with the help of Plackett-Burman design. The highest lipase activity of 57.89 units per gram of dry fermented substrate (U/gds) was observed with the substrate of mustard oil cake in four days of fermentation.
\end{abstract}

Key words: lipase, mustard oil cake, Plackett-Burman design, Yarrowia lipolytica. .

\section{Introduction}

Lipases (triacylglycerol acylhydrolases, EC 3.1.1.3) are one of the most important classes of industrial enzymes. They hydrolyse triglycerides into diglycerides, monoglycerides, glycerol and fatty acids. In recent years, there has been an increasing interest in the study of lipases mainly due to their potential applications as medicines (digestive enzymes), food additives (flavour modifying enzymes), clinical reagents (glyceride-hydrolysing enzymes) and cleaners (detergent additives) (Sharma et al., 2001). Additionally, a promising application field for lipases is in the biodegradation of plastics such as polyhydroxyalkanoates (PHA) and polycaprolactone (PCL) (Jaeger et al., 1995; Mochizuki et al., 1995). Lipases would be economically manufactured in solid state fermentation.

Solid state fermentation (SSF) is defined as the fermentation of solids in the absence of free water; however, the substrate must possess enough moisture to support the growth and metabolism of microorganisms. Recently, several reports have been published indicating the application of this culture in upgrading the food and industrial wastes and in the production of fine chemicals and enzymes. The utilization of by-products and wastes from food and industrial sources has several advantages over submerged fermentation such as superior productivity, simple techniques, reduced energy requirements, low wastewater output, improved product recovery and the reduction in production costs (Ashok, 2003). In SSF, any type of substrate, including industrial wastes, could be used to enhance the production of enzymes because of their richness in fatty acids, triacylglycerols and /or sugars. The use of cheap raw materials would diminish the operating costs of the process. Moreover, total capital investment for lipase production has been reported to be significantly lower in solid state fer- 
mentation than in submerged fermentation (Castilho et al., 2000). Most studies on lipolytic enzymes production with bacteria, fungi and yeasts have been performed in submerged fermentation; however, there are only few reports on lipase synthesis in solid state fermentation. In recent years, considerable research has been carried out using agricultural wastes, which are renewable and abundantly available to produce value-added products. For example babassu oil cake (Gombert et al., 1999), olive cake and sugar cane bagasse (Cordova et al., 1998), gingelly oil cake (Kamini et al., 1998), wheat bran (Mahadik et al., 2002), rice bran (Rao et al., 1993), Jatropha curcas seed cake (Mahanta et al., 2008), niger seed oil cake (Imandi et al., 2010a), and palm kernel cake (Imandi et al., 2010b) have been used as the substrates for lipase production.

India is one of the leading producers of mustard rape seed along with Canada, USA, and some of the European countries. The production in India is about 5.7 million metric tons every year (FAO, 1994). Mustard seeds contain $30-35 \%$ oil and 34-39\% protein (Singhal, 1986). Mustard oil cake (MOC) is prepared from the seeds of Brassica cumpestris (mustard). It is a valuable by-product left after the extraction of oil and is known as mustard oil cake. After extracting the oil from the seed, about $60 \%$ of residue is left as a cake which is available to the livestock industry. The composition of mustard cake varies with the variety, growing conditions and processing methods. These cakes contain $1-12 \%$ ether extract depending upon the method of oil extraction. The protein has a good balance of essential amino acids and relatively high methionine content (Prasad, 1978). However, low palatability of mustard cake is said to be the main problem for its utilization in ruminant diets. This problem is attributed to its glucosinolate content which yields hot and pungent metabolites upon hydrolysis due to the action of endogenous enzymes (Bell, 1984). Ruminants appear to be less susceptible to the toxic effects of glucosinolates compared with pigs and poultry. This is probably the result of glucosinolates being relatively unhydrolysed in the rumen.

Even though a large number of agricultural / food residues have been worked out as suitable substrates for SSF (Raimbault, 1998), there is no report on SSF of mustard oil cake so far to the best of our knowledge. Hence an attempt is made in this paper to utilize the MOC as a substrate for the production of lipase by solid state fermentation. It was under taken to optimize the key process variables, including incubation time, inoculum level, initial moisture content, carbon level, and nitrogen level of the medium for the production of lipase using this oil cake under SSF.

\section{Materials and Methods}

\section{Substrate}

Mustard oil cake (Brassica napus), procured from a local oil extracting unit of Vizianagaram, India, was used as the substrate. It was dried at $60{ }^{\circ} \mathrm{C}$ for $72 \mathrm{~h}$ to reduce the moisture content to around $5 \%$, and ground to the desired size $(2 \mathrm{~mm})$.

\section{Microorganism and growth conditions}

Yarrowia lipolytica NCIM 3589, obtained from National Chemical Laboratory, Pune, India, was used throughout the study. The culture was maintained on MGYP slants having the composition (\%): malt extract 0.3 , glucose 1.0 , yeast extract 0.3 , peptone 0.5 and agar agar 2.0 . The $\mathrm{pH}$ of the medium was adjusted to 6.4-6.8 and culture was incubated at $30^{\circ} \mathrm{C}$ for $48 \mathrm{~h}$. Sub-culturing was carried out once in 2 weeks and the culture was stored at $4{ }^{\circ} \mathrm{C}$.

\section{Inoculum and media preparation}

The Yarrowia strain was cultivated in a medium containing peptone $5 \mathrm{~g}$, yeast extract $3 \mathrm{~g}$ and sodium chloride $3 \mathrm{~g}$ per liter of distilled water. The cells were cultivated in this medium at $30{ }^{\circ} \mathrm{C}$ on a shaker at $200 \mathrm{rpm}$ for $24 \mathrm{~h}$ (Imandi et al., 2008). Ten grams of substrate was weighed into a $250 \mathrm{~mL}$ Erlenmeyer flask and to this a supplemental salt solution was added to the desired moisture level. The composition of the salt solution was as follows $(\% \mathrm{w} / \mathrm{w})$ : $\mathrm{KH}_{2} \mathrm{PO}_{4}: 0.1 ; \mathrm{MgSO}_{4} .7 \mathrm{H}_{2} \mathrm{O}: 0.05 ; \mathrm{CaCl}_{2}: 0.01 ; \mathrm{NaCl}: 0.01$; $\mathrm{H}_{3} \mathrm{BO}_{3}$ : 0.00005; $\mathrm{CuSO}_{4} .5 \mathrm{H}_{2} \mathrm{O}: 0.000004$; KI: 0.00001; $\mathrm{FeCl}_{3} .4 \mathrm{H}_{2} \mathrm{O}: \quad 0.00002 ; \quad \mathrm{ZnSO}_{4} \cdot 7 \mathrm{H}_{2} \mathrm{O}: \quad 0.00004$; $\mathrm{MnSO}_{4} \cdot \mathrm{H}_{2} \mathrm{O}: 0.00004$ (Imandi, 2008). Out of various compounds tried, glucose and urea were ultimately selected as carbon and nitrogen sources respectively as per the Plackett-Burman design (Plackett and Burman, 1946). The contents were thoroughly mixed and autoclaved at $121{ }^{\circ} \mathrm{C}$ (15 psi) for $20 \mathrm{~min}$.

\section{Solid state fermentation and extraction of lipase}

The sterilized substrate along with media as shown in the above section was inoculated with $2 \mathrm{~mL}$ of inoculum. The contents were mixed thoroughly and incubated in a slanting position at $30^{\circ} \mathrm{C}$. All the experiments were carried out and samples were withdrawn after 4 days of incubation. The crude enzyme from the fermented material was recovered by simple extraction method. For this, the fermented substrate was mixed thoroughly with $100 \mathrm{~mL}$ of distilled water and the contents were agitated for $1 \mathrm{~h}$ at the room temperature in a rotary shaker at $150 \mathrm{rpm}$. At the end of extraction, the liquid was filtered off through Whatman number 1 filter paper and the resulting clear filtrate was used for lipase assay.

\section{Lipase assay}

Lipase activity was assayed by the colorimetric method of Winkler and Stuckmann, (1979) by measuring the micromoles of 4-nitrophenol released from 4-nitrophenyl palmitate. One unit of lipase activity was defined as the enzyme amount that releases $1 \mu \mathrm{mol}$ of $p$-nitrophenol 
per minute under assay conditions. Enzyme activity was expressed as units/gram of the initial dry substrate (U/gds).

\section{Experimental design and optimization}

\section{Plackett-Burman design}

The purpose of this optimization step was to identify which ingredients of the medium had a significant effect on lipase activity. The Plackett-Burman statistical experimental design is a versatile method for screening the important variables. The total number of experiments to be carried out is $K+1$, where $K$ is the number of variables. Each variable is represented at two levels, high and low denoted by $(+)$ and (-) respectively. The statistical software package STATISTICA 6.0 (Stat-Ease Inc., Tulsa, OK, USA) was used for analyzing the experimental data.

The effect of each variable on lipase activity was calculated by using the following equation:

$$
E_{(X i)}=\frac{\sum Y_{(+) i}-\sum Y_{(-) i}}{\frac{L}{2}}
$$

where $E_{(X i)}$ is the effect of levels of the tested variables, $Y_{(+) i}$ and $Y_{(-) i}$ are the lipase activity from the experimental runs in which the variables being tested are added to the medium at their maximum and minimum levels respectively and $L$ is the number of experiments carried out. When the value of concentration effect $\left(E_{(X i)}\right)$ of the tested variable is positive, the influence of the variable is greater at the high concentration, and when it is negative, the influence of the variable is greater at the low concentration.

\section{Results and Discussion}

\section{Effect of incubation time}

The incubation time is an important factor for the production of extra-cellular lipase by the microorganisms (Shirazi et al., 1998). The amount of lipase activity was observed daily during a period of five days. The maximum lipase activity was observed on fourth day as shown in Figure 1. At longer incubation periods, the lipase activity decreased which might be due to the depletion of nutrients, accumulation of toxic end products, and the change in $\mathrm{pH}$ of the medium, or loss of moisture.

\section{Effect of biomass concentration}

Different concentration of biomass were tried to study their effect on lipase activity (Figure 2) so as to find an optimum biomass concentration in the fermentation process. A low biomass concentration may give insufficient biomass causing reduced product formation, whereas a higher biomass concentration may produce too much biomass leading to the poor product formation (Mudgetti, 1986). In our study, the maximum lipase activity $(43.48 \mathrm{U} / \mathrm{gds})$ was obtained with $2 \mathrm{~g} / \mathrm{L}$ biomass concentration.

\section{Effect of initial moisture content}

Moisture content of substrate plays a vital role for the microbial growth and for effecting biochemical activities in SSF (Babu and Rao, 2007). The maximum lipase activity was obtained at $50 \% \mathrm{v} / \mathrm{w}$ initial moisture content as presented in Figure 3. Lipase production was decreased at higher moisture content (probably because of decrease in porosity and hence decrease in gaseous exchange leading to suboptimal growth and less enzyme production as indicated by Silman et al. (1979)) and at lower moisture content (probably low moisture content causes reduction in the solubility of nutrients of the substrate, lowers the degree of swelling, and creates higher water tension as suggested by Perez-Guerra et al. (2003)). Mahanta et al. (2008) reported initial moisture content at $50 \%$ of substrate as ideal for lipase production using Jatropha curcas seed cake as the substrate.

\section{Identification of important nitrogen source using Plackett-Burman design}

A total of ten nitrogen sources were screened through twelve experimental runs as per the Plackett-Burman de-

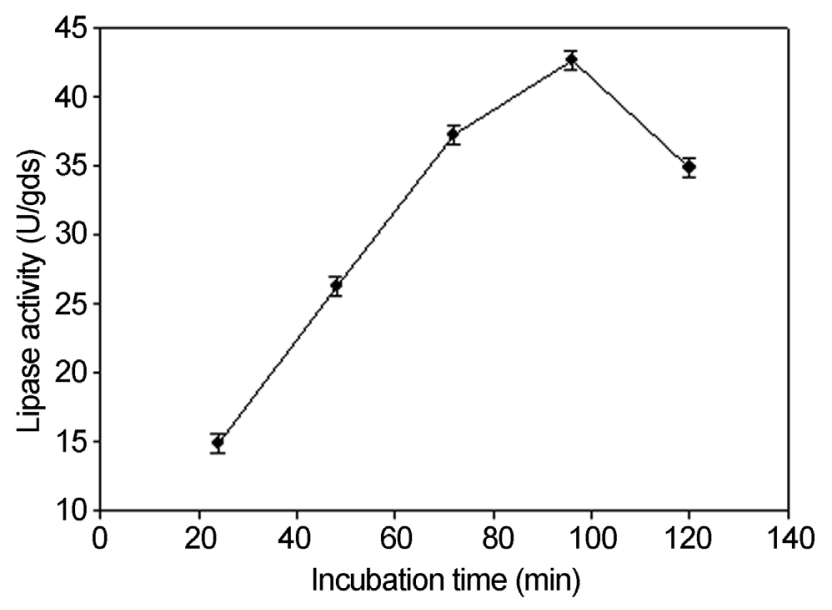

Figure 1 - Effect of incubation time on lipase activity.

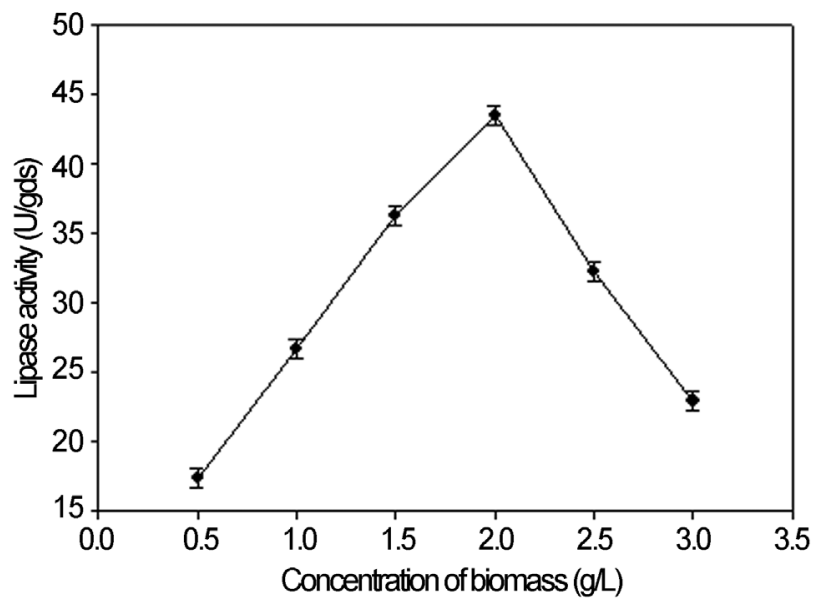

Figure 2 - Effect of biomass concentration on lipase activity. 


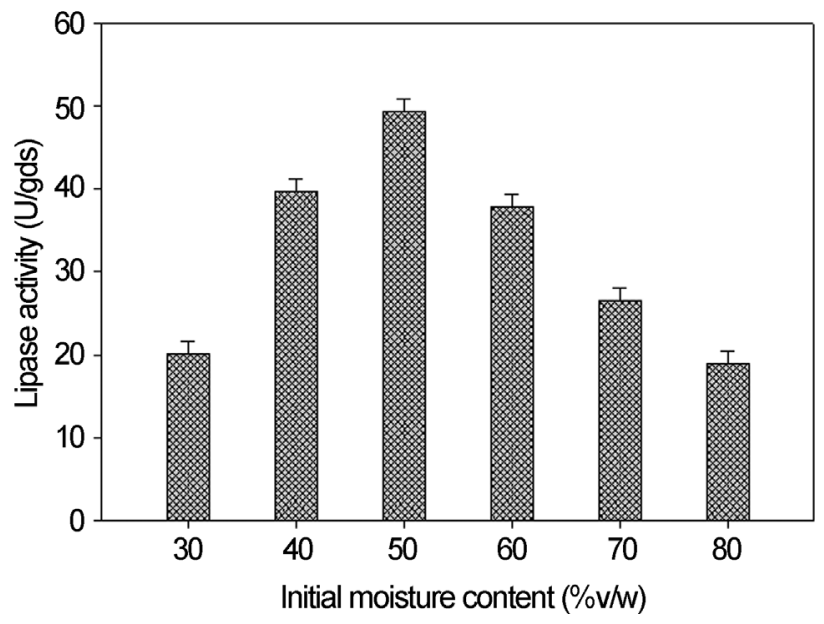

Figure 3 - Effect of initial moisture content on lipase activity.

sign and concentration of nitrogen sources were listed in Table 1. The experimental plan and corresponding lipase production were also shown in Table 1. The pareto graph (Figure 4) was used to show the effect of all nitrogen sources (both organic and inorganic) on lipase production. A p-value of less than 0.05 for the four variables viz., urea, yeast extract, peptone, and malt extract indicates that they are significant. From the statistical analysis, it was also found that lipase production was affected by the above four nitrogen sources as evident from their F-values and p-values that were shown in Table 2. In addition, the coefficient of determination $\left(R^{2}\right)$ of the model was found to be 0.9996 which explains the $99.96 \%$ variability of the data. Urea had the confidence level of more than $95 \%$ in comparison to the other variables and thus considered to be highly

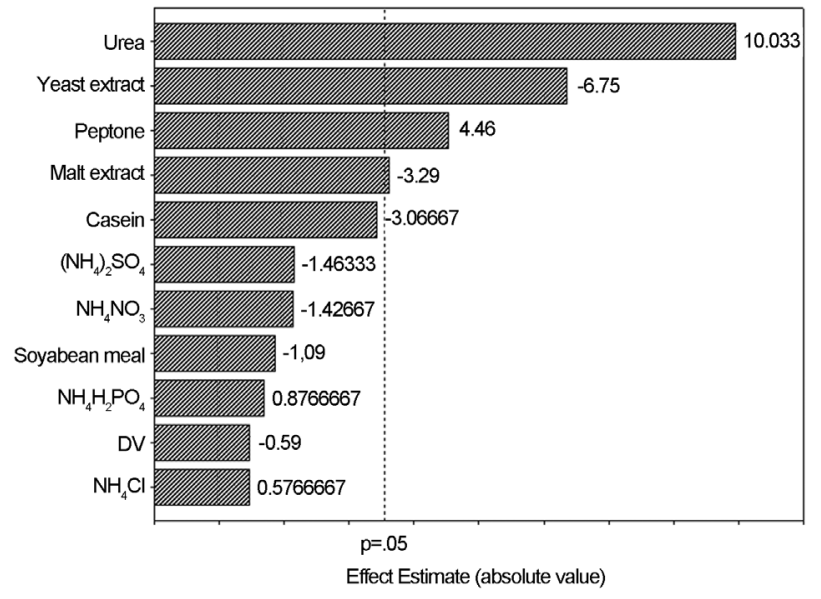

Figure 4 - Pareto graph showing effect of various nitrogen sources on lipase production based on the observation of Plackett-Burman design.

significant for lipase production. Here one dummy variable (DV) was employed to evaluate the standard errors of the experiment. Further studies were conducted by taking urea at different concentrations. Figure 5 shows that 1.5 ( $\%$ $\mathrm{w} / \mathrm{w}$ ) of urea yielded maximum lipase activity. However, at higher levels the production was reduced due to the inhibitory effects of urea.

\section{Identification of important carbon source using Plackett-Burman design}

Five carbon sources were screened by eight experimental runs. The experimental plan and corresponding lipase production were shown in Table 3. The pareto graph (Figure 6) was used to show the effect of all the carbon sources on lipase production. A p-value less than 0.05 for

Table 1 - Plackett-Burman experimental design matrix for screening of various nitrogen sources for lipase production.

\begin{tabular}{|c|c|c|c|c|c|c|c|c|c|c|c|c|c|}
\hline \multirow[t]{2}{*}{ Run no. } & \multirow[t]{2}{*}{ Levels } & \multicolumn{11}{|c|}{ Variables $(\% \mathrm{w} / \mathrm{w})$} & \multirow{2}{*}{$\begin{array}{l}\text { Lipase } \\
\text { activity } \\
\text { (U/gds) }\end{array}$} \\
\hline & & $\begin{array}{c}\text { Soyabea } \\
\text { n meal }\end{array}$ & $\begin{array}{l}\text { Yeast } \\
\text { extract }\end{array}$ & Peptone & Casein & $\begin{array}{c}\text { Malt } \\
\text { extract }\end{array}$ & Urea & $\mathrm{NH}_{4} \mathrm{H}_{2} \mathrm{PO}_{4}$ & $\left(\mathrm{NH}_{4}\right)_{2} \mathrm{SO}_{4}$ & $\mathrm{NH}_{4} \mathrm{Cl}$ & $\mathrm{NH}_{4} \mathrm{NO}_{3}$ & DV & \\
\hline & + & 5.0 & 5.0 & 5.0 & 5.0 & 5.0 & 3.0 & 3.0 & 3.0 & 3.0 & 3.0 & - & \\
\hline & - & 1.0 & 1.0 & 1.0 & 1.0 & 1.0 & 0.5 & 0.5 & 0.5 & 0.5 & 0.5 & - & \\
\hline 1 & & + & - & + & - & - & - & + & + & + & - & + & 45.91 \\
\hline 2 & & + & + & - & + & - & - & - & + & + & + & - & 29.92 \\
\hline 3 & & - & + & + & - & + & - & - & - & + & + & + & 36.12 \\
\hline 4 & & + & - & + & + & - & + & - & - & - & + & + & 51.46 \\
\hline 5 & & + & + & - & + & + & - & + & - & - & - & + & 29.23 \\
\hline 6 & & + & + & + & - & + & + & - & + & - & - & - & 45.04 \\
\hline 7 & & - & + & + & + & - & + & + & - & + & - & - & 49.27 \\
\hline 8 & & - & - & + & + & + & - & + & + & - & + & - & 39.23 \\
\hline 9 & & - & - & - & + & + & + & - & + & + & - & + & 45.34 \\
\hline 10 & & + & - & - & - & + & + & + & - & + & + & - & 48.82 \\
\hline 11 & & - & + & - & - & - & + & + & + & - & + & + & 43.82 \\
\hline 12 & & - & - & - & - & - & - & - & - & - & - & - & 43.14 \\
\hline
\end{tabular}


the three variables viz., glucose, sucrose, and fructose indicates that they are significant. From the statistical analysis,

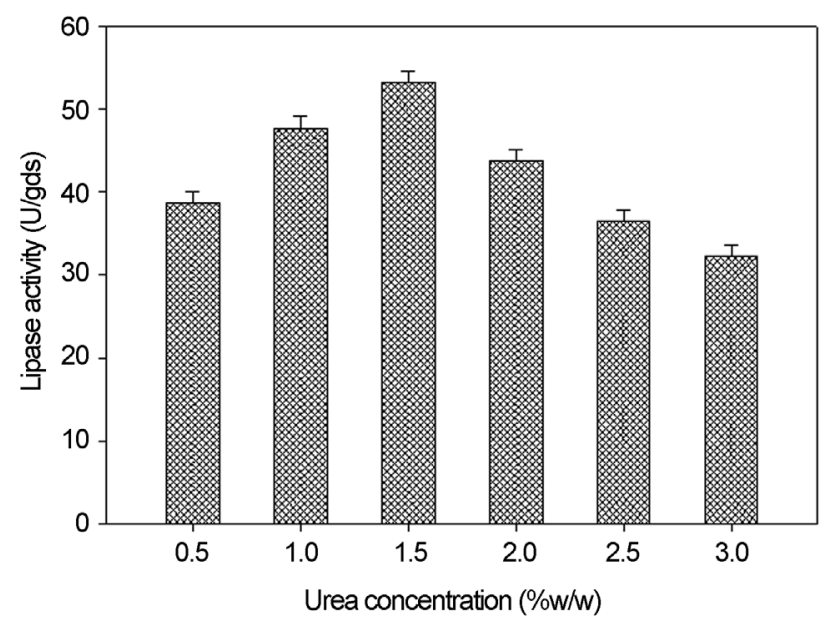

Figure 5 - Effect of urea concentration on lipase activity.

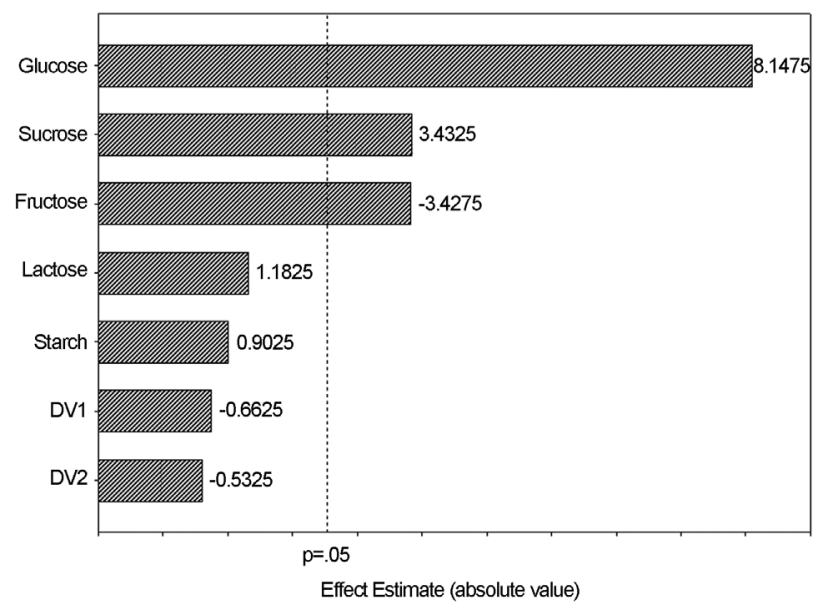

Figure 6 - Pareto graph showing effect of various carbon sources on lipase production based on the observation of Plackett-Burman design. it was also found that lipase production was affected by the above three carbon sources as evident from their F-values and $p$-values which were shown in Table 4. In addition, the coefficient of determination $\left(R^{2}\right)$ of the model was 0.9996 which explains the $99.96 \%$ variability of the data. Glucose had a confidence level of above $95 \%$ in comparison to other variables and thus considered to be highly significant for lipase production. Two dummy variables (DV1 \& DV2) were employed to evaluate the standard errors of the experiment. Figure 7 presents the results of different concentrations of glucose on lipase activity.

\section{Conclusions}

The mustard oil cake demonstrated good microbial growth and enzyme production as evident by its chemical composition. Marine yeast Yarrowia lipolytica NCIM 3589 was used for the fermentation. The presence of MOC with

Table 2 - Effects for various nitrogen sources on lipase production from the results of Plackett-Burman design.

\begin{tabular}{lccc}
\hline Variables & Effect $(E)$ & t-value & p-value \\
\hline Soyabean meal & -1.09000 & -4.3187 & 0.144856 \\
Yeastextract & -6.75000 & -26.7445 & $0.023793^{\mathrm{a}}$ \\
Peptone & 4.46000 & 17.6712 & $0.035988^{\mathrm{a}}$ \\
Casein & -3.06667 & -12.1506 & 0.052276 \\
Malt extract & -3.29000 & -13.0355 & $0.048742^{\mathrm{a}}$ \\
Urea & 10.03333 & 39.7535 & $0.016011^{\mathrm{a}}$ \\
$\mathrm{NH}_{4} \mathrm{H}_{2} \mathrm{PO}_{4}$ & 0.87667 & 3.4735 & 0.178454 \\
$\left(\mathrm{NH}_{4}\right)_{2} \mathrm{SO}_{4}$ & -1.46333 & -5.7979 & 0.108731 \\
$\mathrm{NH}_{4} \mathrm{Cl}$ & 0.57667 & 2.2848 & 0.262638 \\
$\mathrm{NH}_{4} \mathrm{NO}_{3}$ & -1.42667 & -5.6527 & 0.111470 \\
$\mathrm{DV}$ & -0.59000 & -2.3377 & 0.257335 \\
\hline
\end{tabular}

Standard error $=0.252389$.

${ }^{\mathrm{a}}$ Significant at $\mathrm{p} \leq 0.05$.

Table 3 - Plackett-Burman experimental design matrix for screening of different carbon sources for lipase production.

\begin{tabular}{|c|c|c|c|c|c|c|c|c|c|}
\hline \multirow[t]{2}{*}{ Run no. } & \multirow[t]{2}{*}{ Levels } & \multicolumn{7}{|c|}{ Variables $(\% \mathrm{w} / \mathrm{w})$} & \multirow{2}{*}{$\begin{array}{c}\text { Lipase activity } \\
\text { (U/gds) }\end{array}$} \\
\hline & & Glucose & Sucrose & Fructose & Starch & Lactose & DV1 & DV2 & \\
\hline & + & 9 & 9 & 9 & 9 & 9 & - & - & \\
\hline & - & 1 & 1 & 1 & 1 & 1 & - & - & \\
\hline 1 & & - & - & - & + & + & + & - & 43.76 \\
\hline 2 & & + & - & - & - & - & + & + & 49.29 \\
\hline 3 & & - & + & - & - & + & - & + & 46.42 \\
\hline 4 & & + & + & - & + & - & - & - & 54.82 \\
\hline 5 & & - & - & + & + & - & - & + & 39.28 \\
\hline 6 & & + & - & + & - & + & - & - & 48.24 \\
\hline 7 & & - & + & + & - & - & + & - & 41.68 \\
\hline 8 & & + & + & + & + & + & + & + & 51.38 \\
\hline
\end{tabular}

DV: Dummy Variables. 


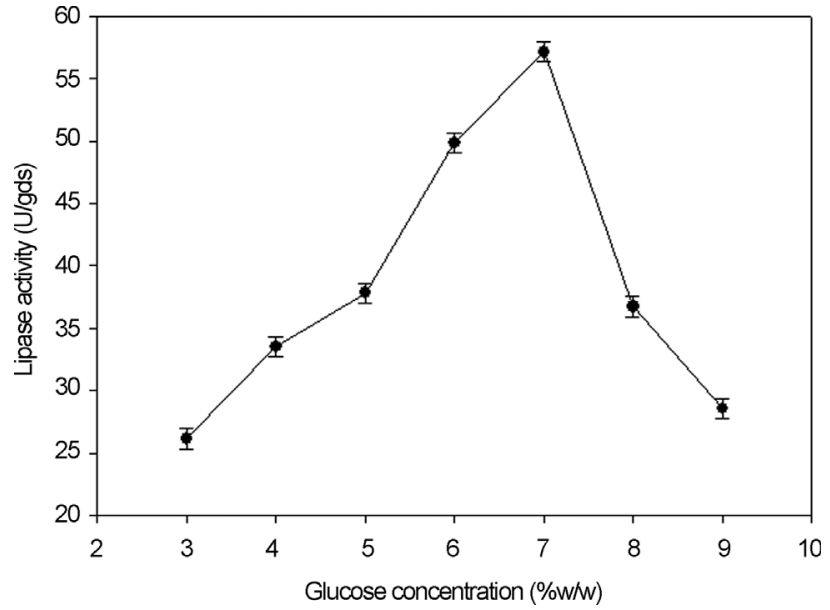

Figure 7 - Effect of glucose concentration on lipase activity.

Table 4 - Effects for various carbon sources on lipase production from the results of Plackett-Burman design.

\begin{tabular}{lccc}
\hline Variables & Effect $(E)$ & t-value & $\mathrm{p}$-value \\
\hline Glucose & 8.14750 & 45.4744 & $0.013997^{\mathrm{a}}$ \\
Sucrose & 3.43250 & 19.1581 & $0.033200^{\mathrm{a}}$ \\
Fructose & -3.42750 & -19.1302 & $0.033248^{\mathrm{a}}$ \\
Starch & 0.90250 & 5.0372 & 0.124761 \\
Lactose & 1.18250 & 6.6000 & 0.095729 \\
DV1 & -0.66250 & -3.6977 & 0.168145 \\
DV2 & -0.53250 & -2.9721 & 0.206624 \\
\hline
\end{tabular}

Standard error $=0.179167$

${ }^{\text {a }}$ Significant at $\mathrm{p} \leq 0.05$.

urea $1.5 \% \mathrm{w} / \mathrm{w}$, glucose $7 \% \mathrm{w} / \mathrm{w}$, and $50 \% \mathrm{v} / \mathrm{w}$ moisture content yielded the maximum lipase activity $(57.89 \mathrm{U} / \mathrm{gds})$ in four days. The high lipase activity achieved in conjunction with the abundantly available mustard oil cake in the state of Andhra Pradesh, India, paved a way for the industrial exploitation of this substrate under solid state fermentation using the indigenous Yarrowia lipolytica NCIM 3589 as a suitable micro organism.

\section{References}

Ashok P (2003) Solid state fermentation. Biochem Eng J 13:8184.

Babu IS, Rao GH (2007) Lipase production by Yarrowia lipolytica NCIM 3589 in solid state fermentation using mixed substrate. Research J Microbiol 2:469-474.

Bell JM (1984) Nutrients and toxicants in rapeseed meal- a review. J Anim Sci 4:996-1010.

Castilho LR, Polato CMS, Baruque EA, Sant Anna Jr GL, Freire DMG (2000) Economic analysis of lipase production by Penicillium restrictum in solid-state and submerged fermentations. Biochem Eng J 4:239-247.

Cordova J, Nemmaoui M, Ismaili-Alaoui M, Morin A, Roussos S, Raimbault M, Benjilali B (1998) Lipase production by solid state fermentation of olive cake and sugar cane bagasse. $\mathrm{J}$ Mol Catal B Enzym 5:75-78.

FAO (1994) Production Year Book. Food and Agricultural Organization of United Nations, Rome.

Gombert AK, Pinto AL, Castilho LR, Freire DMG (1999) Lipase production by Penicillium restrictum in solid-state fermentation using babassu oil cake as substrate. Proc Biochem $35: 85-90$.

Imandi SB (2008) Studies on the production of lipase in solid state fermentation using Artificial Neural Networks and Genetic Algorithms. Ph.D. Thesis, Andhra University, Visakhapatnam, AP, India.

Imandi SB, Bandaru VVR, Somalanka SR, Bandaru SR, Garapati HR (2008) Application of statistical experimental designs for the optimization of medium constituents for the production of citric acid from pineapple waste. Bioresour Technol 99:4445-4450.

Imandi SB, Karanam SK, Garapati HR (2010a) Optimization of process parameters for the production of lipase in solid state fermentation by Yarrowia lipolytica from niger seed oil cake (Guizotia Abyssinica). J Microbial Biochem Technol 2:2833.

Imandi SB, Karanam SK, Garapati HR (2010b) Optimization of media constituents for the production of lipase in solid state fermentation by Yarrowia lipolytica from palm kernal cake (Elaeis guineensis). Adv Biosci Biotechnol 1:115-121.

Jaeger KE, Steinbuchel A, Jendrossek D (1995) Substrate specificities of bacterial polyhydroxyalkanoate depolymerases and lipases: bacterial lipases hydrolyze poly $(\omega$-hydroxyalkanoates). Appl Environ Microbiol 61:3113-3118.

Kamini NR, Mala JGS, Puvanakrishnan R (1998) Lipase production from Aspergillus niger by solid-state fermentation using gingelly oil cake. Proc Biochem 33:505-511.

Mahadik ND, Puntambekar US, Bastawde KB, Khire JM, Gokhale DV (2002) Production of acidic lipase by Aspergillus niger in solid state fermentation. Proc Biochem 38:715-721.

Mahanta N, Gupta A, Khare SK (2008) Production of protease and lipase by solvent tolerant Pseudomonas aeruginosa PseA in solid-state fermentation using Jatropha curcas seed cake as substrate. Bioresour Technol 99:1729-1735.

Mochizuki M, Hirano M, Kanmuri Y, Kudo K, Tokiwa Y (1995) Hydrolysis of polycaprolactone by lipase: effects of draw ratio on enzymatic degradation. J Appl Polymer Sci 55:289296.

Mudgetti RE (1986) Manual of industrial biotechnology. American Society for Microbiology, Washington DC.

Pérez-Guerra N, Torrado-Agrasar A, López-Macias C, Pastrana L (2003) Main characteristics and applications of solid substrate fermentation. Electronic J Environ Agric Food Chem 2:343-350.

Plackett RL, Burman JP (1946) The design of optimum multifactorial experiments. Biometrika 33:305-325.

Prasad A (1978) Evaluation of mustard oil cake available in India. I. Proximate analysis, total lysine and methionine contents. Indian J Nutr Diet 15:159.

Raimbault M (1998) General and microbiological aspects of solid substrate fermentation. Electronic J Biotechnol 1:174-189.

Rao PV, Jayaraman K, Lakshmanan CM (1993) (1993) Production of lipase by Candida rugosa in solid state fermentation. 1: determination of significant process variables. Proc Biochem 28:385-389. 
Sharma R, Chisti Y, Banerjee UC (2001) Production, purification, characterization, and applications of lipases. Biotechnol Adv 19:627-662.

Shirazi SH, Rahman SR, Rahman MM (1998) Production of Extra cellular lipases by Saccharomyces cerevisiae. World J Miocrobiol Biotechnol 14:595-597.

Silman RW, Conway MF, Anderson RA, Bagley EB (1979) Production of aflatoxin in corn by large scale solid state fermentation process. Biotechnol Bioeng 21:1799-1808.
Singhal KK (1986) Oilseed cakes for livestock feeding. NDRI, Karnal.

Winkler UK, Stuckmann M (1979) Glycogen, hyaluronate and some other polysaccharides greatly enhance the formation of exolipase by Serratia marcescens. J Bacterial 138:663670.

All the content of the journal, except where otherwise noted, is licensed under a Creative Commons License CC BY-NC. 